\title{
Opening Pandora's box - Is there any hope of a turn for the better in the employment situation of the Visegrád Four countries?
}

\begin{abstract}
This article presents the employment situation in the Visegrád Four (V4) countries (Poland, Czech Republic, Slovakia and Hungary) in recent years. The extensive economic literature deals with the role the state plays in the area of employment and in revitalising demand in order to deal with economic crisis; it also includes the probable benefits and drawbacks of such measures. The regional economic literature increasingly concerns regional disparities and regional discrepancies at the socio-economic level. Can this phenomenon be observed among regions of sub-regions and, if so, to what extent is this problem exaggerated? My hypothesis states that the employment position of the Visegrád Four is different in relation to the European Union, and within the V4, the human resource position is weak and the level of employment low, which is influenced by several factors, while the four countries have different employment trends. The methodology is the analysis of the available statistical data with the discriminant analysis method.
\end{abstract}

Keywords: employment situation, regional disparities, Visegrád Four, discriminant analysis method

Introduction

In this article, I analyse the situation of a particular group within the European Union, the Visegrád Four, with special regard to its employment and labour market trends. This denomination of the historically-rooted group is currently used in the academic jargon. I wish to find an answer to the question as to whether there are peculiarities in the area of employment in the case of the V4 countries: are the V4 countries moving on similar or different paths, or are they rather undergoing the same extent of development?

History of the Visegrád Four

In 1335, Visegrád Castle, royal seat of the Hungarian kings, was the site of a summit between the Polish, Czech and Hungarian kings at which they agreed to close co-operation in the area of politics and commerce. This inspired their late descendants to a successful central European initiative.

The 'Visegrád 4' (V4) is the unofficial name of the four central European postcommunist countries: Czech Republic; Hungary; Poland; and Slovakia. The Group was originally called the 'Visegrád 3' but, after the split in the Czechoslovakian Republic in 1993, became the Four. The name of the Group was chosen at a meeting held in 
Visegrád, on 15 February 1991, in which participated the Czech President, Václav Havel; the Hungarian Prime Minister, József Antall; and the Polish President, Lech Wałesa. The politicians signed a declaration that the three (now four) countries would closely co-operate on the way towards European integration. After the collapse of the communist system, their co-operation facilitated the transition from totalitarian regime to a free, pluralistic and democratic society.

The Visegrád Four (V4) countries (Czech Republic, Hungary, Poland and Slovakia) form a unique cluster of the European Union, which show many similarities from political, economic and social respects. The countries could converge to the EU average measured at national level in the past years and do not show significant differences; at regional level, however, significant polarization could be observed. (Nagy-Kuttor, 2008)

\section{The economic and labour market situation of the Visegrád Four in recent years}

The change of regime was a crucial event in the case of the Visegrád Four, although the starting point for my thesis is the concept of the 'double transition'. The thesis of double transition is more than about the shocking fact that the economic and social regime change had to take place at the same time in the ex-socialist bloc: the theory suggests that the post-communist transition took place at the same time that these countries, as part of a larger process, were also facing a post-industrial challenge. This challenge had a globalisation-cultural and technological nature in particular. This is not to state that the post-communist countries, including Hungary, provided optimum answers to these problems - moreover, the differences maintaining backwardness were mainly reproduced in these dimensions. None of the post-communist countries can avoid these challenges; they have a paradigmatic nature. In other words: the post-communist countries could not follow the classical welfare models of the 70 s because the models themselves had gone through an essential transformation (Stratégiai Audit, 2007).

The general government deficit is an indicator which expresses the economic trends particularly well. Figure 1 plots a data series for the four countries for the years between 1995 and 2009; it is clear that the curves show a very hectic picture.

At the starting point, the highest government deficit was in the Czech Republic $(-13 \%)$, although this had improved by ten percentage points by the following year.

The curve illustrating the Slovakian data series shows large peaks and lows between 1995 and 2003. Afterwards, the deficit became stable up to 2008, when the economic world crisis created substantial deteriorations in the economies of all the countries.

Hungary's government deficit also showed an adverse trend, with the highest values in the years of the elections, 2002 and $2006(-9 \%)$. Last year, it showed a deficit of $4.5 \%$ compared to GDP.

Finally, the government deficit was relatively favourable in Poland's case compared to the rest of the V4.

Overall, we cannot say that the V4 countries have been in a similar economic situation in the past, or that they are so in the present. 
Figure 1 - Budget balance as percentage of GDP
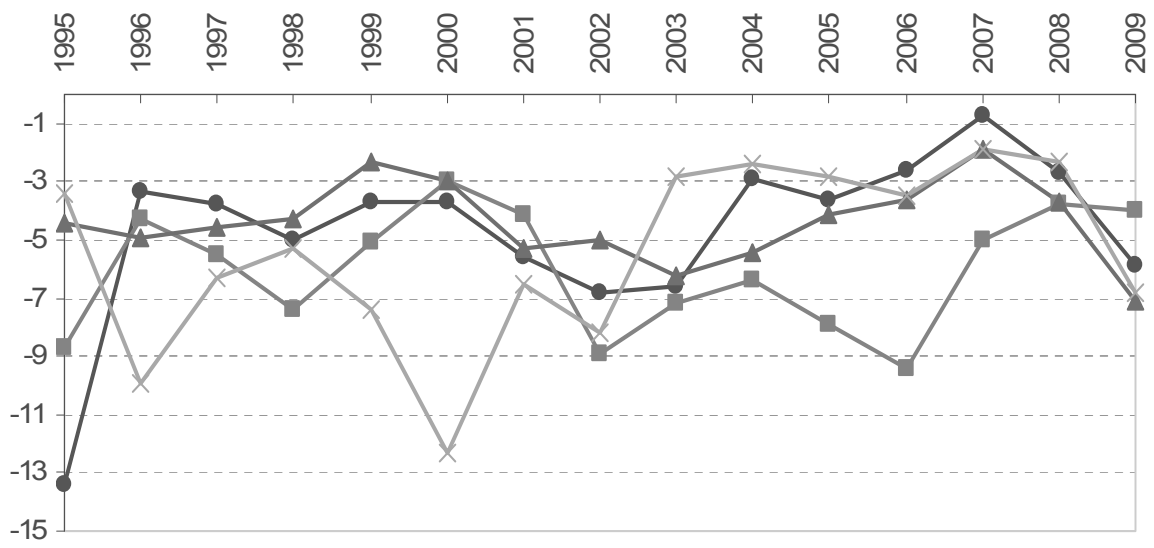

$\multimap$ Czech Republic $\_$-Hungary $\multimap$ Poland $\longleftarrow$ Slovakia

Source: Own compilation on the basis of Eurostat data

Figure 2 illustrates government deficits compared to the Maastricht criterion in both 2000 and 2009 . Slovakia's value of $12.3 \%$ dropped to $6.8 \%$ by 2009 ; however, the initially favourable values deteriorated in the case of the other three countries. Hungary's deficit was $4 \%$ in 2009, which was the most favourable figure among the V4.

Figure 2 - Government deficit as a percentage of GDP, 2000 and 2009

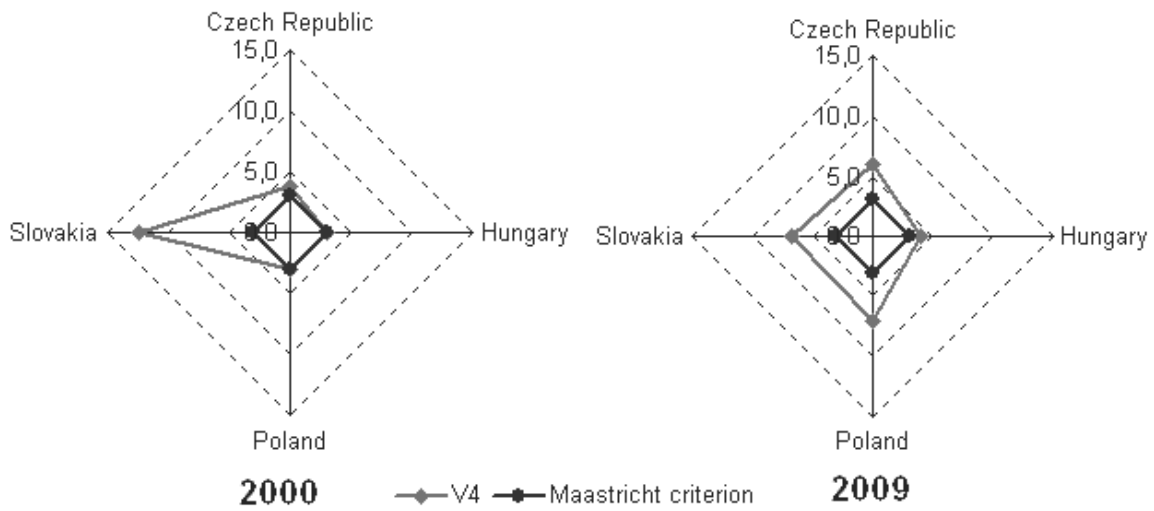

Source: Own compilation on the basis of Eurostat data

The economic situation of the V4 has improved slowly, albeit to differing extents, since 1995. A focus on GDP per capita as a percentage of the EU-27 figure shows that 
the Czech Republic developed the most dynamically (Figure 3), followed by Slovakia, Hungary and, finally, Poland. The GDP per capita of both Poland and Hungary grew unevenly, and with a development that was not as dynamic as in the case of the other two countries. At the same time, the V4 significantly lagged behind the EU-27 average.

\section{Figure 3 - GDP per capita as a percentage of the EU-25 figure}

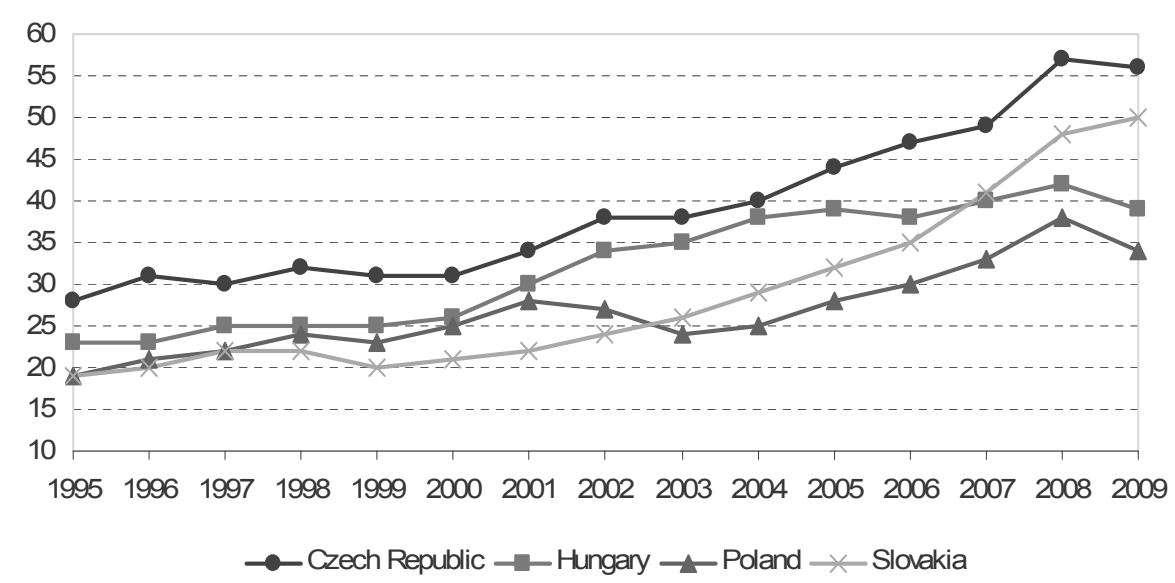

Source: Own compilation on the basis of Eurostat data

In seeking to analyse the economic situation further, we can highlight the percentage growth in GDP in 2007 compared to 1995 (Figure 4). The differences are explicit enough in the case of NUTS2 regions. The regions belonging to the capital cities show considerable growth compared to the 1995 value - they almost doubled - while peripheral regions barely reached $150 \%$ of the 1995 value. Economic growth was, therefore, mainly experienced in regions belonging to the capital or to other large cities.

Slovakia is in the best position among the countries; it has a strengthening economy. In contrast, the picture is rather more differentiated in the case of both Hungary and Poland. The relatively stronger position of the Transdanubian region is clear in Hungary; the same can also be said about the Czech regions. 
Figure 4 - GDP growth per capita (\%) (2007/1995)

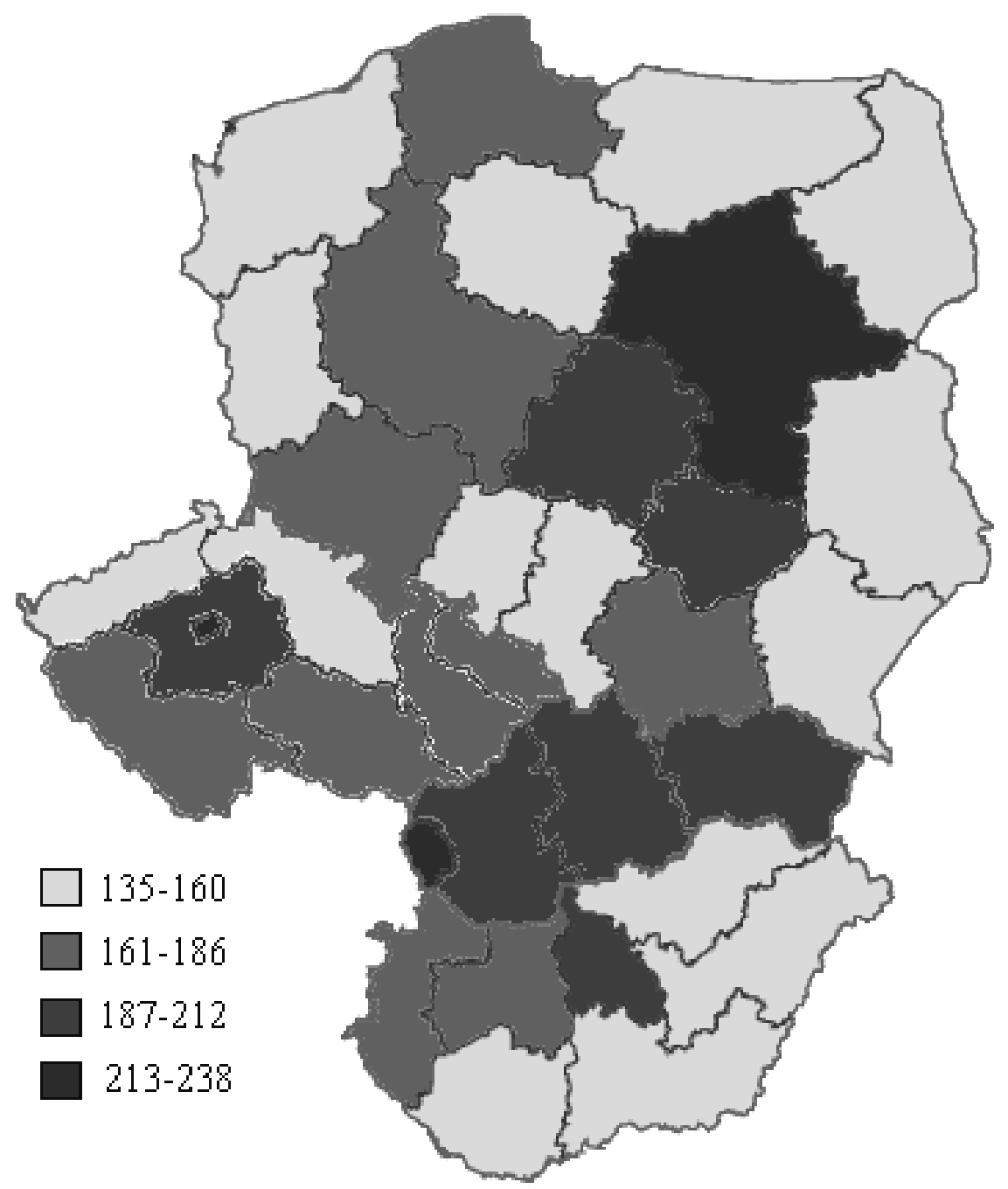

Source: Own compilation on the basis of Eurostat data

Significant discrepancies can also be observed among the countries' NUTS2 regions in terms of GDP per capita as a percentage of the EU-27 figure (Figure 5). The values of the regions belonging to the capital are outstanding. However, there is an obvious general development in the years following 2003 since more and more regions can be found above the average value. 
Figure 5 - Regional GDP per capita as a percentage of the EU-27 figure

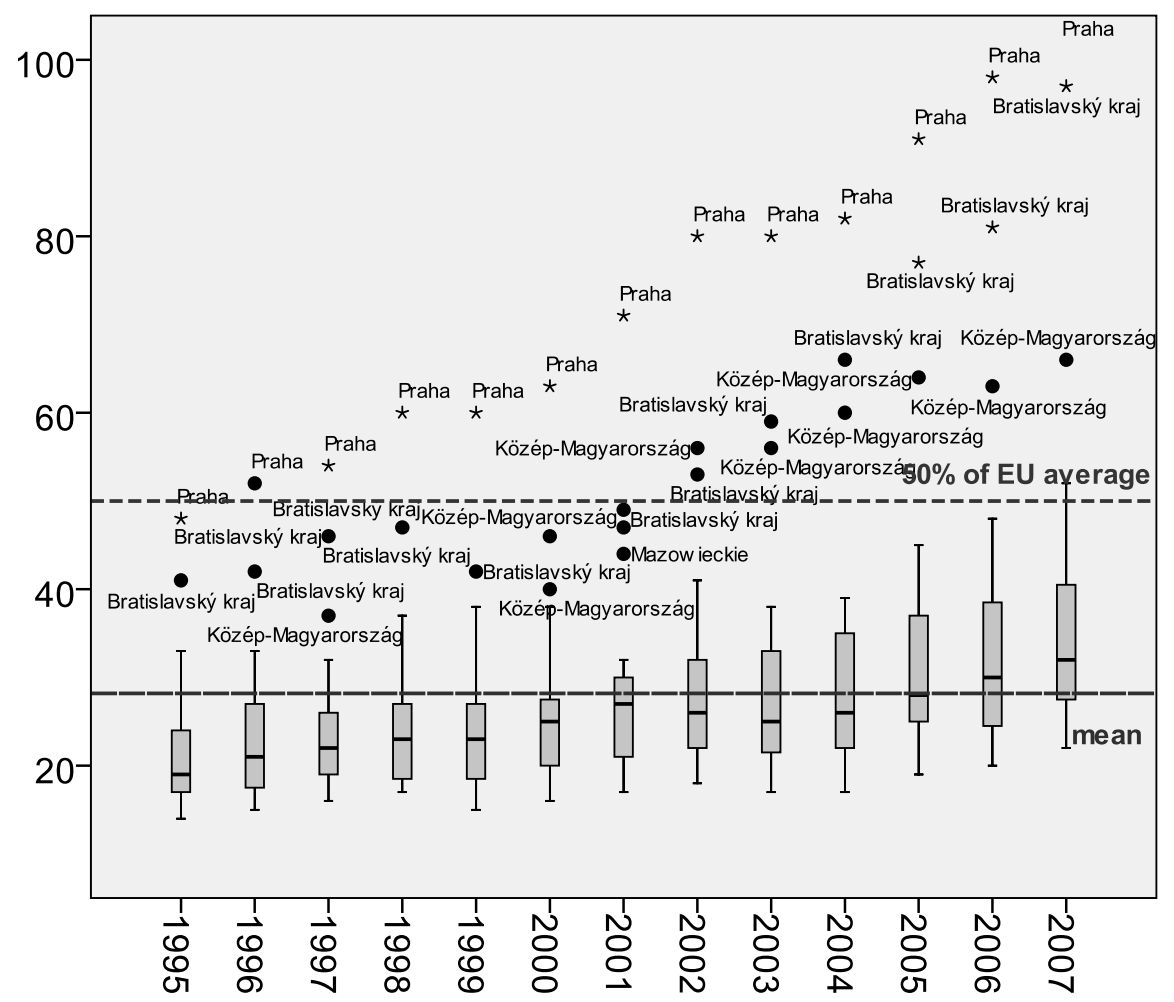

Source: Own compilation on the basis of Eurostat data

Turning to the labour market, we should start with the unemployment and employment rates because these two indicators express the situation most accurately. The unemployment rate (Figure 6) has shown a different picture in each country since 1998.

Poland and Slovakia possessed the highest values as far as 2005, although unemployment has improved since then. The countries have followed appropriate employment policies, as a result of which the labour market situation has improved.

The Czech Republic and Hungary had an evenly low level of unemployment, but it has shown a modest increase in both countries. 
Figure 6 - Unemployment rate (\%) between 1998 and 2009

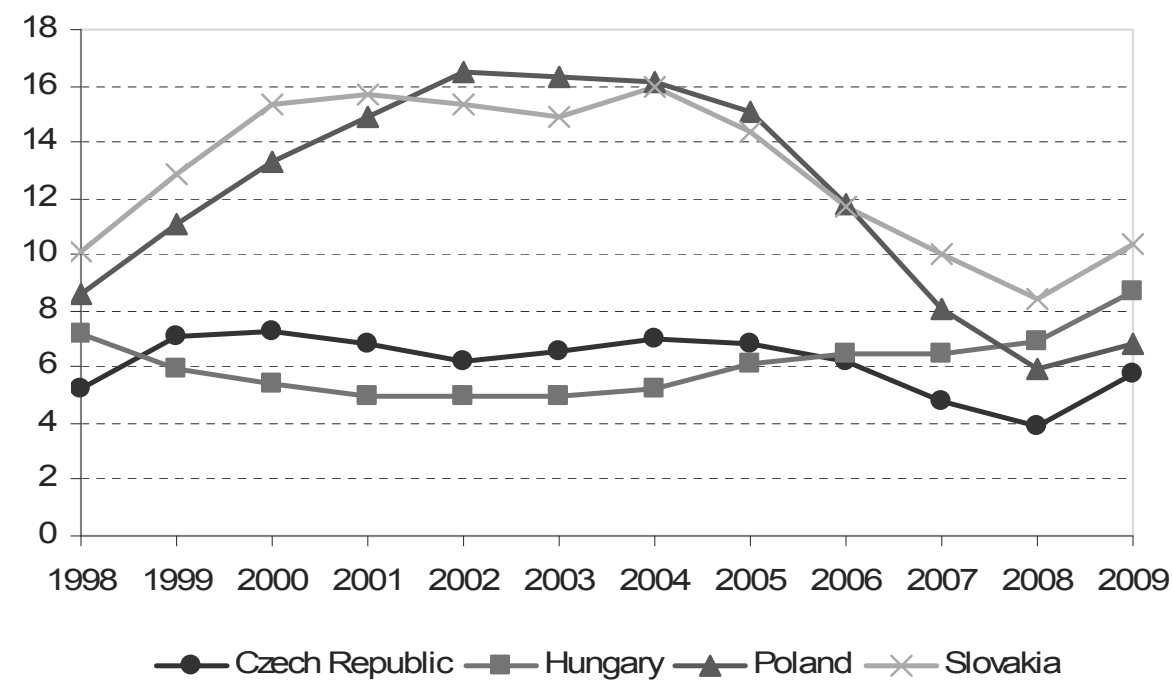

Source: Own compilation on the basis of Eurostat data

The employment rate (Figure 7) is the main indicator describing the labour market. Here, it shows the complementary nature of the employment situation in the cases of Poland and Hungary.

Employment improved in parallel with falling unemployment in Poland. The employment rate was static in Hungary between 2000 and 2007; afterwards, it decreased by $3 \%$.

The employment rate was the most favourable in the Czech Republic, being above $64 \%$ across the whole period. However, the economic crisis saw the employment rate drop even in this country.

The employment rate significantly improved in Slovakia after 2005, the growth rate of which was broken by the economic crisis. 
Figure 7 - Employment rate, 1998-2009 (\%)

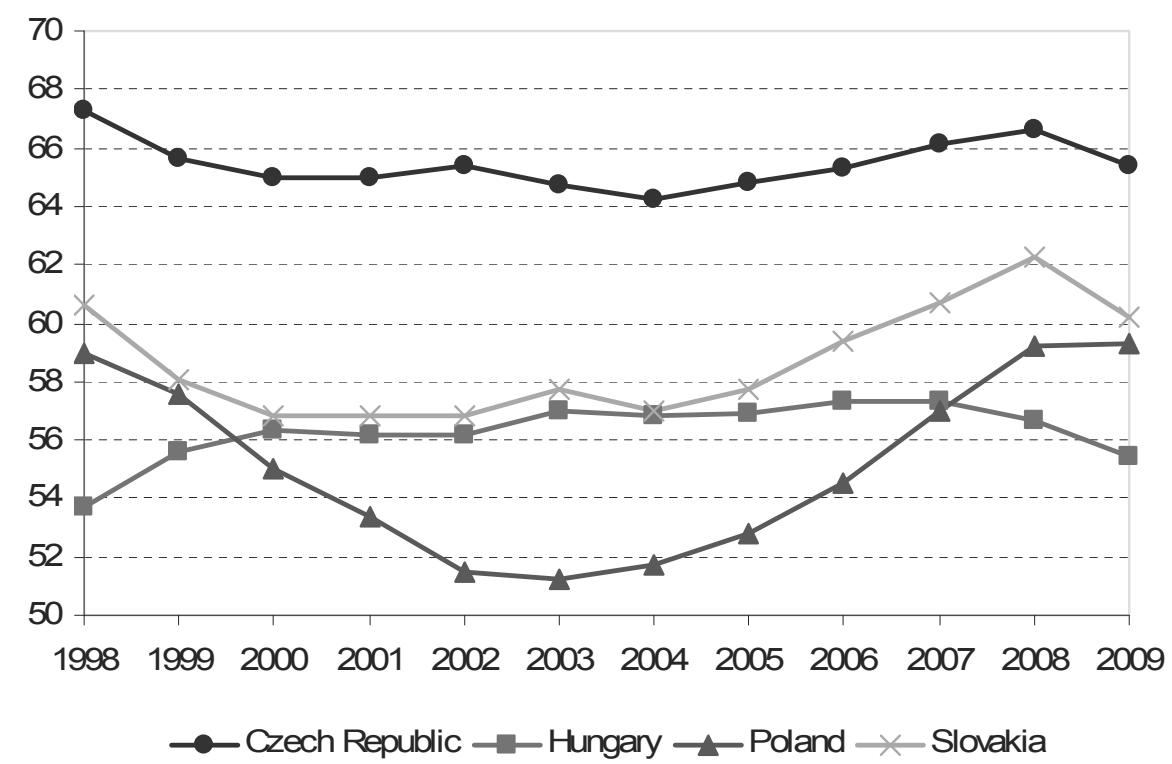

Source: Own compilation on the basis of Eurostat data

Methodology of discriminant analysis (DA)

Discriminant analysis was introduced by Fisher and Mahalanobis. The basis of the method is that every unit of observation is classified into a group according to a predetermined criterion; that is, discriminant analysis is one method of classifying our observations. Its application requires having a discrete (so-called 'classification') variable and one or more quantitative variables. The objective is to decide to what extent we retrieve the original classifications if we try to classify our observations on the basis of the given quantitative variables. This enables an analysis of the extent to which the quantitative variable differentiates the specific classifications.

Several conditions have to be realised for the application of the DA method: the covariance matrices of the groups should not differ significantly; and the variable should possess a normal distribution.

I collected the following indicators about the 35 NUTS2 regions for 2008 on the basis of Eurostat data:

- employment rate $(\%)$

- unemployment rate $(\%)$

- activity rate $(\%)$

- fertility rate $(\%)$

- pupils and students in all levels of education (ISCED 0-6), as a percentage of the total population at the regional level. 
I ran a discriminant analysis after the general one. Before this, a partial correlation by pairs was performed for each indicator so as to be assured of their independence. The original classification was based on GDP growth per capita between 1995 and 2007 and the intention was to find an answer to whether grouping according to GDP growth per capita was valid on the basis of the labour market indicators.

Discriminant analysis produced Figure 8 below. We can see the spread of the specific sub-regions according to the original group classification, taking the labour market indicators into account. 'Developed' regions have spread considerably; that is, not every sub-region fall into this group if we take only the labour market indicators. 'Rapidly developing' regions fall into one group and do not display significant difference. The most 'medium developing' regions are spread considerably around the group centre, while 'slowly developing' regions also display a considerably large spread.

\section{Figure 8 - Canonical discriminant functions}

\section{Canonical Discriminant Functions}

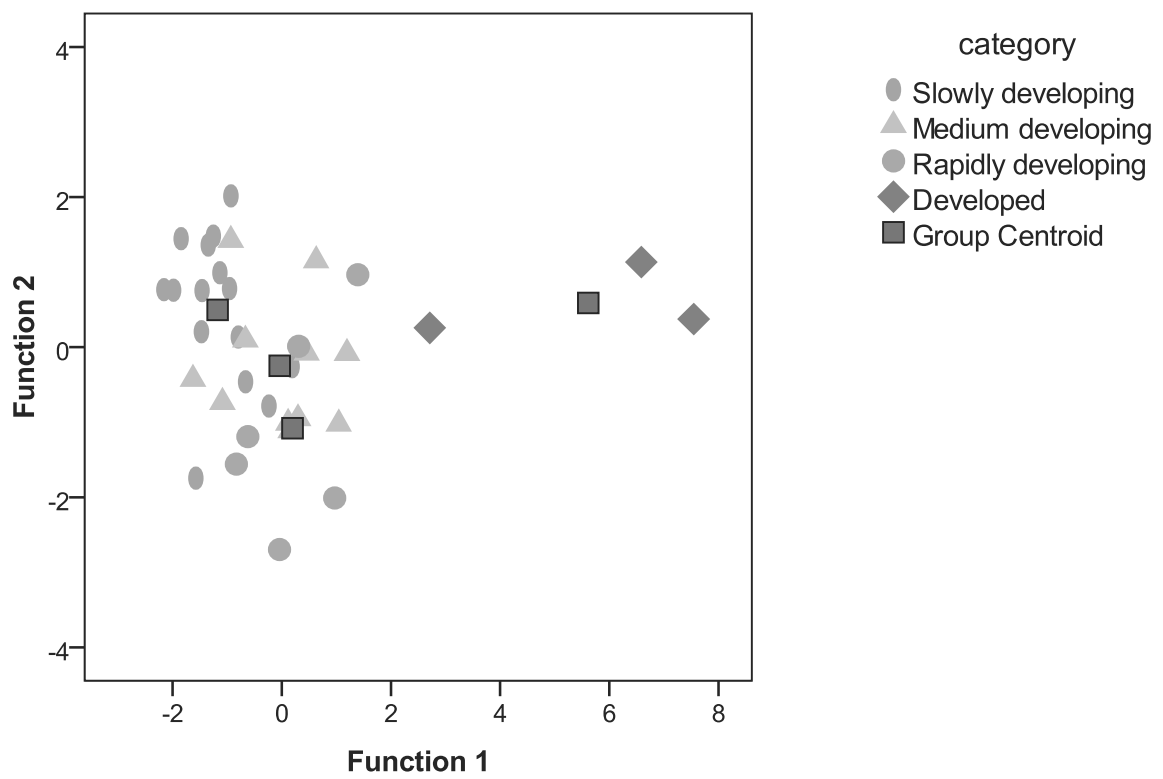

Source: own construction

The final table of the discriminant analysis shows numerically the extent to which the groups, developed as a result of the analysis of the labour market indicators and in accordance with the original classification, match or mismatch the original classification. 
Table 1 - Classification results of discriminant analysis

\begin{tabular}{|c|c|c|c|c|c|c|}
\hline \multicolumn{7}{|c|}{ Classification Results a,b } \\
\hline & \multirow[t]{2}{*}{ Category } & \multicolumn{4}{|c|}{ Predicted Group Membership } & \multirow[t]{2}{*}{ Total } \\
\hline & & $\begin{array}{l}\text { Slowly } \\
\text { devel- } \\
\text { oping }\end{array}$ & $\begin{array}{l}\text { Medium } \\
\text { devel- } \\
\text { oping }\end{array}$ & $\begin{array}{l}\text { Rapidly } \\
\text { devel- } \\
\text { oping }\end{array}$ & Developed & \\
\hline \multirow[t]{4}{*}{ Count } & Slowly developing & 11 & 3 & 1 & 0 & 15 \\
\hline & Medium developing & 3 & 6 & 2 & 0 & 11 \\
\hline & Rapidly developing & 0 & 3 & 3 & 0 & 6 \\
\hline & Developed & 0 & 1 & 0 & 2 & 3 \\
\hline \multirow[t]{4}{*}{$\%$} & Slowly developing & 73.3 & 20.0 & 6.7 & 0 & 100.0 \\
\hline & Medium developing & 27.3 & 54.5 & 18.2 & 0 & 100.0 \\
\hline & Rapidly developing & 0 & 50.0 & 50.0 & 0 & 100.0 \\
\hline & Developed & 0 & 33.3 & 0 & 66.7 & 100.0 \\
\hline
\end{tabular}

a. $62.9 \%$ of original grouped cases correctly classified

b. $51.4 \%$ of cross-validated grouped cases correctly classified

According to the table, eleven of the fifteen slowly developing regions are in the expected position, and they are evidently in need of support either from the labour market or from the legal classification point of view. Three of the remaining four regions fall into the medium developing category, while one goes in the rapidly developing class, according to the unemployment indicators.

Six of the eleven medium developing regions are in the expected place, while five actually belong in one of the two other groups referred to thus far.

Three of the six rapidly developing regions are in the appropriate group while the others belong more appropriately to the category of medium developing country.

Finally, two out of the three developed regions are again in the appropriate group, while the remaining one falls into the medium developing category, according to the labour-market indicators.

In conclusion, the Visegrád Four NUTS2 regions, established on the basis of a GDP growth per capita classification, do not match the groups formed according to the labour market indicators. Regional disparity can be experienced in the labour market within regions as well. However, the discriminant analysis did not supply information about its extent; it needs further calculation.

At the same time, I regard my hypothesis as valid, because the difference between the extreme values is more significant in the case of NUTS2 regions than at the level of the countries involved. There is an enormous gap between the most under-developed and the most developed regions from the point of view of the labour market. 


\section{Conclusion}

Recent decades for the V4 countries have been famous for the exponential growth of globalization. Every state, every community and every person was hit by a jet speed spreading of the influence and interdependency of worldwide trading networks. State boundaries are no longer applicable. Kofi Annan said: 'It has been said that arguing against globalization is like arguing against the laws of gravity.' Countries, historically brought to a consensus, enter new trading unions and become every day stronger economic players. (Oslanec, 2009)

In conclusion, we can establish that the four countries have, in recent years, moved on four different paths of development. Their economic and labour market situation is totally different. The historical ties and even the currently satisfactory relationships have not resulted in a common approach to development. Their employment situation could improve via a more efficient co-operation, or even common employment principles, but I think that the countries are each trying to fight the unfavourable employment situation on their own. It is fully predictable that they could achieve more if they pooled their forces together.

\section{References}

Ágoston, László, Tibor Dessewffy and Szabolcs Szajp (2007) Hungary's Strategic Audit 2007 ITD Hungary: Budapest, p. 1-134.

Chytilek, Roman and Petr Kaniok (2006) 'Territoriality and Eurosceptic Parties in V4 Countries' Constructing New Identities in Transforming Europe: Enlargement and Integration: are they compatible? Seminar held in Helsinki, Finland, p. 1-15.

Nagy, Zoltán and Dániel Kuttor (2008) 'Analysis of the territorial disparities in the Visegrád Four Countries: Measurement and visualisation of territorial processes at regional level in Central Europe' Regions: The Dilemmas of Integration and Competition Regional Studies Association Annual International Conference, 27-29 May, Seaford, p. 1-13.

Oslanec, Roman (2009) How will the role of the state in V4 countries change as a result of the financial crisis? Essay Competition VISION 2025, p. 1-8.

Šipikal, Miroslav and Jana Parízková (2009): Regional innovation strategies in V4 countries 3rd Central European Conference in Regional Science, Kosice, p. 1425-1434. 